\title{
Anabolic treatments for osteoporosis in postmenopausal women
}

\author{
Neelam Hassan ${ }^{1 *} \quad$ Celia L. Gregson ${ }^{1} \quad$ Jon H. Tobias ${ }^{1}$ \\ ${ }^{1}$ Translational Health Sciences, Bristol Medical School, University of Bristol, Musculoskeletal Research Unit, Southmead Hospital, Bristol, UK
}

\begin{abstract}
Antiresorptive agents are generally recommended as first-line treatment for osteoporosis in postmenopausal women. These drugs suppress bone resorption but do not rebuild bone, limiting their efficacy. Antiresorptive use is further hampered by concerns over rare side effects, including atypical femoral fractures and osteonecrosis of the jaw. Anabolic treatments overcome limitations of antiresorptive treatment by stimulating new bone formation, reducing the risk of fracture with greater efficacy. This review summarises the latest trial data for the three anabolic agents currently available for the treatment of osteoporosis in postmenopausal women: teriparatide, abaloparatide, and romosozumab. Data from head-to-head studies comparing anabolic and antiresorptive treatments are reviewed. At present, anabolic treatments are generally reserved for use in patients with severe osteoporosis at very high fracture risk; the factors limiting their more widespread use are discussed together with how this may change in the future.
\end{abstract}

\section{Keywords}

Anabolic, Osteoporosis, Teriparatide, Abaloparatide, Romosozumab, Postmenopausal

\section{Peer Review}

The peer reviewers who approve this article are:

1. Tahir Masud, Department of Geriatric Medicine, Nottingham University Hospital, Nottingham, UK; Geriatric Research Unit, Department of Clinical Research, University of Southern Denmark, Odense, Denmark

Competing interests: No competing interests were disclosed.

2. Daniela Merlotti, Department of Medicine, Surgery and Neurosciences, University of Siena, Siena, Italy Competing interests: No competing interests were disclosed. 
*Corresponding author: Neelam Hassan (Neelam.hassan@bristol.ac.uk)

Competing interests: Jon H. Tobias has received speaker fees from UCB. Neelam Hassan and Celia L. Gregson declare that they have no competing interests.

Grant information: Neelam Hassan is funded by the Elizabeth Blackwell Institute for Health Research, University of Bristol, and the Wellcome Trust Institutional Strategic Support Fund.

The funders had no role in study design, data collection and analysis, decision to publish, or preparation of the manuscript.

Copyright: (C) 2021 Hassan $\mathrm{N}$ et al. This is an open access article distributed under the terms of the Creative Commons Attribution License, which permits unrestricted use, distribution, and reproduction in any medium, provided the original work is properly cited.

How to cite this article: Hassan N, Gregson CL and Tobias JH. Anabolic treatments for osteoporosis in postmenopausal women. Faculty Reviews 2021 10:(44) https://doi.org/10.12703/r/10-44

Published: 06 May 2021, Faculty Reviews 10:(44) https://doi.org/10.12703/r/10-44 


\section{Introduction}

In osteoporosis, loss of bone tissue occurs, leading to skeletal fragility and an increase in fracture risk ${ }^{1}$. One in three women and one in five men over the age of 50 will sustain an osteoporotic fracture at some point in their lifetime ${ }^{2}$. Fractures of the hip and spine in particular are associated with high levels of morbidity and mortality ${ }^{3-5}$. Antiresorptive treatments, such as oral (e.g. alendronic acid and risedronate) and intravenous (e.g. zoledronate) bisphosphonates and subcutaneous denosumab, are the most widely used antiresorptive treatments for osteoporosis, reducing the risk of vertebral and hip fractures by $40-70 \%$ and $40-53 \%$, respectively ${ }^{6-11}$. Their use is limited for several reasons ${ }^{12}$. Oral bisphosphonates are commonly associated with side effects such as gastrointestinal disturbance, which, together with difficult dosing regimens, contributes to the poor adherence rates $\operatorname{seen}^{13}$. In addition, suppression of bone resorption is associated with rare but serious side effects such as osteonecrosis of the jaw (ONJ) and, when prolonged, atypical femoral fractures (AFFs). Finally, since previously lost bone cannot be restored by antiresorptive agents, only finite gains in bone mineral density (BMD) can be achieved, limiting efficacy in severely affected individuals.

Anabolic treatments for osteoporosis, which act to stimulate bone formation, may overcome these limitations. At least theoretically, these agents are not associated with an increased risk of ONJ or AFF, are not limited in terms of BMD increment, and restore previously lost bone, making them effective in patients with severe osteoporosis. Here, we summarise the trial data for the three anabolic agents currently available for the treatment of osteoporosis in postmenopausal women, namely teriparatide, abaloparatide, and romosozumab, and consider their use in clinical practice.

\section{Teriparatide}

Trial data

Teriparatide (PTH 1-34) is a recombinant fragment of parathyroid hormone (PTH). It was developed after rats exposed to intermittent PTH were found to show a predominant bone formation response $\mathrm{e}^{14}$. This contrasted with increased bone resorption and bone loss following prolonged continuous exposure to PTH, as occurs in patients with primary hyperparathyroidism ${ }^{15}$. This observation eventually led to the Fracture Prevention Pivotal Trial, published in 2001, in which postmenopausal women with a vertebral fracture were assigned to daily subcutaneous injections of $20 \mu \mathrm{g}$ or $40 \mu \mathrm{g}$ of teriparatide or placebo for 21 months $^{16}$. Following the $20 \mu \mathrm{g}$ dose of teriparatide, risks of vertebral and nonvertebral fracture were found to be reduced by $65 \%$ and $53 \%$, respectively, compared with placebo.

Subsequently, in a head-to-head trial, teriparatide was found to be superior to alendronate at increasing BMD at the spine and hip, although the more clinically relevant outcome of fracture risk was not investigated ${ }^{17}$. However, teriparatide was found to reduce fracture risk in glucocorticoid-induced osteoporosis by $90 \%$ compared to alendronate over 18 months ${ }^{18}$. Another trial demonstrated that teriparatide reduced vertebral fractures by $50 \%$ compared to risedronate over 12 months in patients with acute painful vertebral fractures ${ }^{19}$. Although, of note, fracture outcomes were not the primary endpoints in any of these studies. More recently, the VERO trial investigated the effect of teriparatide vs. risedronate on incident radiographic vertebral fracture in women with severe osteoporosis ${ }^{20}$. After 24 months, there was a relative risk reduction of $56 \%$ in the teriparatide arm compared to the risedronate arm. The incidence of nonvertebral and clinical fractures was also reduced in the teriparatide arm by $34 \%$ and $52 \%$, respectively. Recently, a systematic review and meta-analysis of 23 teriparatide trials determined specific efficacy against hip (but not upper limb) fractures of $56 \%$ in patients with osteoporosis ${ }^{21}$.

\section{Limitations and clinical use}

Teriparatide is thought to be generally safe, though treatment duration is limited to 24 months because of a theoretical risk of osteosarcoma that was seen in rodents receiving high-dose teriparatide $^{22}$. That said, this side effect has not been observed in humans in post-marketing surveillance ${ }^{23}$. In terms of side effects, $3 \%$ of patients suffer from persistent hypercalcaemia, and transient bone loss may occur at cortical bone sites such as the distal forearm ${ }^{16}$, both of which result from teriparatide's co-stimulatory action on bone resorption.

In common with other anabolic agents, teriparatide is given by subcutaneous injection and must be stored in a refrigerator. Since the injection is administered on a daily basis, this can reduce patient uptake and adherence ${ }^{24}$. Attempts to develop alternative routes of administration have thus far been unsuccessful. The uptake of teriparatide has also been limited in many countries owing to its relatively high cost. This is likely to improve following the recent development of generic teriparatide and biosimilars. Four teriparatide preparations are now available for use in the UK, including two teriparatide biosimilars and a chemically synthesized generic version of teriparatide, which was launched in 2020. A further strategy to limit costs is to reduce the frequency of administration to once or twice weekly, which is also associated with gains in BMD, though to a lesser extent than that observed with daily treatment $\mathrm{t}^{25,26}$.

Teriparatide is mainly used as a second-line treatment in severe osteoporosis after the failure of bisphosphonates or denosumab $^{27}$. Concern has been raised as to whether this sequence might be detrimental, given teriparatide stimulates bone formation, which is reduced by antiresorptive agents as a result of coupling of bone formation to resorption. Transient hip BMD loss is reported for at least a year in patients transitioning from antiresorptives to teriparatide, particularly post denosumab ${ }^{28}$, suggesting teriparatide should ideally be used as a first-line treatment for severe osteoporosis to optimise its anabolic effect.

In patients who are already on an antiresorptive, continuing the antiresorptive whilst adding in teriparatide may be an effective strategy to mitigate bone loss. The DATA-Switch study, published in 2015, examined the effect on BMD of (a) 24 months of teriparatide followed by 24 months of denosumab, 
(b) 24 months of both teriparatide and denosumab followed by 24 months of denosumab only, and finally (c) 24 months of denosumab followed by 24 months of teriparatide ${ }^{29}$. Switching from teriparatide to denosumab resulted in BMD continuing to increase, whereas switching from denosumab to teriparatide resulted in progressive or transient bone loss. The highest increases in femoral neck and total hip BMD were seen in those receiving combination therapy, although this was not significantly different from the teriparatide to denosumab arm. A recent systematic review and meta-analysis of 19 trials also showed that combination therapy (i.e. teriparatide plus most commonly a bisphosphonate) was superior to teriparatide alone in terms of increasing $\mathrm{BMD}^{30}$, which may be explained by the bisphosphonate ameliorating teriparatide-induced increases in cortical porosity ${ }^{28}$.

Importantly, whether BMD losses seen following switch from antiresorptives to teriparatide translates to a reduction in anti-fracture efficacy remains unclear, as most studies examined BMD as the primary outcome rather than fracture risk. Of note, the VERO trial demonstrated substantial anti-fracture efficacy of teriparatide, even though $59 \%$ of patients in the teriparatide arm had previously been treated with bisphosphonates. In subgroup analyses, no evidence was seen for a difference in the anti-fracture efficacy of teriparatide in treatment-naïve patients vs. those who had previously been treated with bisphosphonates $^{31}$.

A further consideration is that cessation of teriparatide treatment may be followed by relatively rapid BMD $\operatorname{loss}^{32}$. It is now standard practice to follow a 2-year course of teriparatide with an antiresorptive agent to maintain BMD gains ${ }^{29,32}$, though the antiresorptive best suited for this purpose remains unclear. An alternative strategy would be to repeat the teriparatide treatment course. However, concerns about osteosarcoma have limited such investigation, although it is almost certain that these concerns have been overstated when compared to real-world human data ${ }^{23}$. To date, only one study has attempted to investigate teriparatide re-treatment after an initial 2-year course ${ }^{33}$; $30 \mu \mathrm{g}$ of teriparatide was administered to both men and women with osteoporosis for 24 months, then withdrawn for a "drug holiday" of 12 months, before being reintroduced for another 12 months. The response to teriparatide re-treatment, in terms of BMD gain and increases in bone turnover markers, was significantly attenuated compared to the initial course. Although retreatment restored BMD to pre-drug holiday levels, there was no further increase in BMD. This resistance to retreatment with teriparatide remains unexplained, although various mechanisms have been postulated, such as receptor downregulation or increase in negative regulators of bone formation, e.g. Dickkopf-1 (Dkk1) ${ }^{34}$.

\section{Abaloparatide}

Trial data

Abaloparatide is a synthetic peptide analogue of human PTH-related protein, developed with the aim of decoupling PTH's anabolic action from stimulation of bone resorption, thereby reducing the risk of adverse effects such as hypercalcaemia, and avoiding transient bone loss at cortical sites as seen with teriparatide. Abaloparatide and teriparatide have differences in affinity for the two stable conformations (RG and $\mathrm{R}^{0}$ ) of the PTH1 receptor ${ }^{35}$. Abaloparatide has a 1,600-fold greater affinity for the $\mathrm{R}^{0}$ conformation of the receptor compared with teriparatide. It is postulated that abaloparatide's greater affinity for the $\mathrm{R}^{0}$ conformation results in a greater increase in bone formation than bone resorption.

Abaloparatide was approved for use in the USA for the treatment of postmenopausal women with osteoporosis at high risk of fracture in 2017, following the Abaloparatide Comparator Trial in Vertebral Endpoints (ACTIVE) trial ${ }^{36}$. This was a phase III, double-blind, three-arm study in which postmenopausal women with osteoporosis were randomised to receive $80 \mu \mathrm{g}$ daily subcutaneous abaloparatide, $20 \mu \mathrm{g}$ daily subcutaneous teriparatide, or placebo for 18 months. Those receiving abaloparatide had an $86 \%$ relative risk reduction in vertebral fractures compared to placebo, with a $43 \%$ relative risk reduction in nonvertebral fractures. BMD at the lumbar spine, femoral neck, and total hip increased rapidly compared to placebo at 6, 12, and 18 months. Though teriparatide led to a slightly smaller reduction in nonvertebral fractures $(28 \%)$ overall, abaloparatide and teriparatide showed similar anti-fracture efficacy. There was a lower incidence of 4-hour post-dose hypercalcaemia with abaloparatide compared to teriparatide; however, serious adverse events were similar across the three arms of the trial. That said, there were more adverse events leading to discontinuation after abaloparatide (9.9\%) than teriparatide $(6.8 \%)$ or placebo $(6.1 \%)$. In the subsequent ACTIVExtend study, women who had completed the original ACTIVE study were treated with 24 months of alendronate ${ }^{37}$. There was a relative risk reduction of vertebral (39\%), clinical (34\%), and major osteoporotic fractures $(50 \%)$ in the abaloparatide to alendronate arm vs. the placebo to alendronate arm.

\section{Limitations and clinical use}

As a high-cost daily subcutaneous injection, many of the limitations of teriparatide are shared by abaloparatide. Although abaloparatide was approved for use in the USA in 2017, in 2018 the European Medicines Agency refused marketing approval in the European Union (EU). Poor compliance to good clinical practice at two study sites, the inability of the study documentation to convincingly demonstrate efficacy for nonvertebral fracture prevention, and an observed increase in palpitations and heart rate were cited as reasons for this rejection $^{38}$.

\section{Romosozumab}

\section{Trial data}

Romosozumab, a monoclonal antibody against sclerostin, was developed as an anabolic osteoporosis treatment following the discovery that loss-of-function mutations in the SOST gene, which produces sclerostin, underlies the rare high bone mass disorder sclerosteosis ${ }^{39}$. In contrast to the PTH analogues, romosozumab stimulates bone formation but also simultaneously 
reduces bone resorption ${ }^{40}$. Romosozumab was recently approved as a new anabolic osteoporosis treatment in the USA and in Europe following two phase III trials confirming its anti-fracture efficacy.

The FRAME trial investigated the effect of monthly subcutaneous romosozumab $210 \mathrm{mg}$ vs. placebo on fracture risk $^{41}$. After 12 months, romosozumab conveyed 73\%, 36\%, and $25 \%$ relative risk reductions in vertebral fractures, clinical fractures, and nonvertebral fractures, respectively, although the relative risk reduction for nonvertebral fracture was weak (relative risk [RR] 0.75 [95\% confidence interval (CI) 0.53-1.05], $P=0.1$ ). However, in post-hoc analyses, excluding the low-risk Colombian cohort, there was stronger evidence of a decrease in nonvertebral fracture risk in the romosozumab arm with a relative risk reduction of $42 \%(P=0.01)^{42}$. Romosozumab resulted in a marked gain in BMD (lumbar spine BMD increased by $13 \%$ over 12 months), with bone turnover markers indicating this was due to a combination of increased bone formation and reduced bone resorption. In the FRAME Extension study, women who had received subcutaneous romosozumab or placebo for 12 months were then switched to open-label subcutaneous denosumab every 6 months for 24 months $^{43}$, after which a relative risk reduction in new vertebral fractures and nonvertebral fractures persisted in the romosozumab arm compared to the placebo arm. Moreover, the increase in BMD in the first 12 months of the romosozumab arm was maintained over the subsequent 24 months during treatment with denosumab, after which on average $10.5 \%$ and $5.2 \%$ increases in lumbar spine and total hip BMD, respectively, were seen.

The subsequent ARCH study investigated the effectiveness of a sequential treatment regimen consisting of anabolic romosozumab consolidated by the antiresorptive alendronic acid ${ }^{44}$. $\mathrm{ARCH}$ was a randomised double-blind multicentre trial that compared romosozumab for 12 months followed by transition to alendronic acid for 12 months vs. alendronic acid alone for 24 months. In contrast to the FRAME trial, the study population was of relatively high fracture risk $(96 \%$ had had a vertebral fracture, $9 \%$ a recent hip fracture). Fracture risk reductions were apparent at 12 months in the romosozumab arm (37\% reduction in vertebral fractures, $28 \%$ in clinical fractures, and $26 \%$ in nonvertebral fractures). By 24 months, there was a relative risk reduction of $48 \%$ in new vertebral fractures, $27 \%$ in clinical fractures, $19 \%$ in nonvertebral fractures, and $38 \%$ reduction in hip fractures in those receiving romosozumab then alendronic acid vs. alendronic acid throughout.

\section{Limitations and clinical use}

Though romosozumab is associated with a marked anabolic response, this appears to be relatively short lived. For example, in the FRAME study, while the osteoblast marker P1NP initially increased in the romosozumab group by approximately $150 \%$, it had normalised by 9 months $^{41}$. To ensure sufficient trial duration to evaluate effects on fracture risk, a sequential therapy was needed, whereby romosozumab was followed by an antiresorptive agent. The same is also likely to apply to clinical use of this treatment.

The effect of a second course of romosozumab was investigated in an extension of the phase II dose-finding study ${ }^{45}$. Postmenopausal women with low BMD (T-score $\leq-2.0$ and $\geq-3.5$ ) received romosozumab or placebo from months 0-24, followed by placebo or denosumab from months 24-36, and then romosozumab from months 36-48. The second course of romosozumab resulted in further BMD increases of $12.4 \%$ at the lumbar spine and $6 \%$ at total hip in the romosozumab-placebo-romosozumab arm, similar to the BMD increases seen with the initial course (12\% and 5.5\%, respectively). In the romosozumab-denosumab-romosozumab arm, the second course of romosozumab generated smaller BMD gains ( $2.3 \%$ at the lumbar spine, unchanged at total hip), although the second romosozumab course appeared to counteract the BMD loss that would be expected after discontinuation of denosumab, contrasting with what is seen with the switch from denosumab to teriparatide ${ }^{29}$. Romosozumab's action, of reducing bone resorption as well as stimulating bone formation, is likely to account for this difference in response. It is important to note that fracture risk reduction was not assessed, so it is unclear whether repeated romosozumab treatment courses would enhance anti-fracture efficacy.

Whilst no safety signals were seen in the FRAME study, an increase in major adverse cardiovascular events (MACE) was noted in the romosozumab arm over the first 12 months in the ARCH study (2.5\% vs. $1.9 \%$ in the alendronic acid arm). A recent systematic review and meta-analysis investigating the effect of romosozumab on cardiovascular outcomes demonstrated a $39 \%$ increase in four-point MACE (including death, myocardial infarction, stroke, and heart failure) amongst postmenopausal women and older men with osteoporosis over a period of 12-36 months ${ }^{46}$. This finding was again largely driven by the results of the ARCH trial.

Several hypotheses have been suggested to explain this difference ${ }^{47,48}$. As ARCH focussed only on women with severe osteoporosis, the study population was older in comparison to that of FRAME, with a higher baseline prevalence and risk of cardiovascular disease. However, there was no imbalance of cardiovascular risk factors between the romosozumab and alendronic acid arms. There is some evidence that those genetically predisposed to lower sclerostin expression in bone have a greater risk of major adverse cardiovascular events ${ }^{49}$; however, to what extent this predicts the effect of sclerostin inhibitors on vascular tissue remains unclear. Another possible explanation is that the ARCH study used a bisphosphonate as the comparator; a previous trial found that 18-monthly zoledronate over 6 years reduced all-cause mortality, possibly indicating a protective effect of bisphosphonates on risk of cardiovascular events rather than an adverse effect of romosozumab ${ }^{50,51}$. However, this has not been borne out in a subsequent systematic review and meta-analysis of 38 randomised clinical trials ${ }^{52}$. The alternative possibility is that the difference in rates of 
MACE observed in the ARCH trial was due to chance, particularly as no effect was observed in the placebo-controlled FRAME trial $^{48}$.

Nonetheless, concern about the cardiovascular safety profile led to romosozumab being given only restricted approval to selected groups with severe osteoporosis by the European Medicines Agency in October 2019 after initially being refused.

\section{When should an anabolic agent be prescribed for osteoporosis?}

As discussed above, anabolic drugs for osteoporosis serve to increase BMD and reduce fracture risk quickly and to a greater extent than both placebo and conventional antiresorptive therapies (Table 1). Increases in BMD, particularly at the hip, appear to be greatest when anabolic agents are used de novo rather than after antiresorptive use. It is therefore attractive to consider using anabolic agents as first-line treatment in certain patient groups. For example, since the anti-fracture efficacy of anabolic agents appears to be greatest at the spine, it may be that these agents are best used in those at high risk of vertebral fractures. Another strategy is to target those at very high risk of imminent fracture, defined as a high risk of fracture within the next $12-24$ months. It can be difficult to determine precisely which individuals are at imminent risk of fracture. Prior fracture type, age, sex, falls risk, comorbidities, and medications can all increase individual fracture risk $^{53}$. However, recency of prior fracture has been found to be the key predictor of imminent fracture risk ${ }^{54}$. The risk of a second major osteoporotic fracture is highest immediately after the first fracture, and most subsequent osteoporotic fractures occur within 5 years of the initial fracture ${ }^{55-57}$.

Cut-offs for identifying individuals with a very high fracture risk as assessed using the FRAX algorithm have recently been proposed, which take into account recency of fracture ${ }^{58,59}$. An important consideration is that current fracture risk calculators such as FRAX are primarily geared towards predicting hip fractures rather than vertebral fractures. This has the advantage that greater weighting is applied to hip fractures, the most costly in terms of healthcare spending, than other fractures. However, although anabolic drugs reduce hip fracture risk, they are more efficacious at reducing the risk of vertebral fractures, reflecting the fact that hip fractures arise from multiple factors beyond low $\mathrm{BMD}^{2}$.

Despite demonstrating greater clinical efficacy than antiresorptives, currently teriparatide is the only anabolic drug for osteoporosis available through the National Health Service (NHS) in the UK, where its use is restricted by high cost; the same is also expected to apply to romosozumab. In the UK, access to high-cost medicines is governed by the National Institute for Health and Care Excellence (NICE), with recommendations largely based on considerations of cost effectiveness. NICE last reviewed the use of teriparatide in 2018 both teriparatide and romosozumab underwent a full economic evaluation as part of a National Institute for Health Research (NIHR)-funded Health Technology Assessment (HTA) ${ }^{61}$, which is likely to be considered when NICE next review these treatment options. This HTA found that although both teriparatide and romosozumab are highly effective at preventing fragility fractures, the incremental cost-effectiveness ratios (ICERs) for both interventions exceed the commonly applied threshold of $£ 30,000$ per quality-adjusted life-year (QALY) compared with no treatment across a range of probabilities for fracture risk. The authors noted that estimates given of incremental net monetary benefit in patients at very high fracture risk were uncertain, as they were based on only a very small proportion of the simulated population. The cost-effectiveness specifically in individuals at high risk of vertebral fractures was not examined; therefore, it remains unknown whether these anabolic agents may indeed be cost-effective in this population. Whilst hip fractures continue to be the main driver in cost-effectiveness analyses, the use of anabolic drugs in cost-limited systems such as the NHS is likely to continue to be restricted.

A systematic review of cost-effectiveness analyses for osteoporosis drugs across 15 countries was recently updated to include emerging data on sequential therapy starting with

Table 1. Effect of anabolic treatments on vertebral and nonvertebral fracture risk in postmenopausal women with osteoporosis.

\begin{tabular}{|c|c|c|c|c|c|}
\hline Drug & Trial & Comparator & $\begin{array}{l}\text { Duration } \\
\text { (months) }\end{array}$ & $\begin{array}{c}\text { Vertebral } \\
\text { fracture RRR }\end{array}$ & $\begin{array}{l}\text { Non-vertebral } \\
\text { fracture RRR }\end{array}$ \\
\hline \multirow[t]{3}{*}{ Teriparatide } & $\mathrm{FPT}^{16}$ & Placebo & 21 & $65 \%$ & $53 \%$ \\
\hline & VERO 20 & Risedronate & 24 & $56 \%$ & $34 \%$ \\
\hline & ACTIVE $^{36}$ & Placebo & 18 & $80 \%$ & $28 \%^{b}$ \\
\hline Abaloparatide & ACTIVE $^{36}$ & Placebo & 18 & $86 \%$ & $43 \%$ \\
\hline \multirow[t]{2}{*}{ Romosozumab } & FRAME $^{41}$ & Placebo & 12 & $73 \%$ & $25 \%$ \\
\hline & $\mathrm{ARCH}^{44 a}$ & Alendronic acid & 24 & $\begin{array}{l}37 \% \text { (12 months) } \\
48 \% \text { (24 months) }\end{array}$ & $\begin{array}{l}\text { 26\% (12 months) } \\
19 \% \text { (24 months) }\end{array}$ \\
\hline
\end{tabular}

aRomosozumab for 12 months followed by alendronic acid for 12 months vs. alendronic acid for 24 months. ${ }^{b}$ Nonsignificant (relative risk 0.72 [95\% confidence interval $0.42-1.22$ ], $P=0.22$ ). RRR = relative risk reduction 
teriparatide or abaloparatide followed by alendronic acid compared with no treatment, placebo, or alendronic acid alone ${ }^{62}$. The results from the three studies included in the analysis were mixed, with ICERs strongly affected by the very high costs of abaloparatide and teriparatide. One study indicated that the cost of generic teriparatide or biosimilars would need to be $65-85 \%$ lower than the originator for sequential treatment to be cost-effective ${ }^{63}$. A more recent study assessing the costeffectiveness of sequential treatment starting with romosozumab followed by alendronic acid compared to alendronic acid alone for postmenopausal women at high risk of fracture in Sweden demonstrated an ICER of $€ 33,732$, well below the Swedish threshold of $€ 60,000$ per QALY ${ }^{64}$.

The development and marketing of generic teriparatide and biosimilars may offer some hope of re-appraising the cost-effectiveness equations. To enable cost-effectiveness models that are more suitable for evaluating anabolic drugs for osteoporosis, and to define groups to whom these should be offered, further work is needed to improve our understanding of the economic consequences of vertebral fractures and to develop more accurate strategies for individualised vertebral fracture risk assessment.

\section{Conclusions}

Therapeutic options for osteoporosis have recently increased with the availability of new anabolic therapies: teriparatide, which has been available for many years, increases both bone formation and bone resorption; abaloparatide (not licensed in Europe) acts in a similar manner to teriparatide but may have less tendency to stimulate bone resorption; romosozumab increases bone formation whilst reducing bone resorption. However, though overcoming limitations of antiresorptive treatment in terms of clinical efficacy and rare side effect risks, anabolic treatment use is likely to remain limited by cost in particular. The parenteral route of administration required for all currently available anabolic agents may also limit patient uptake and adherence. Looking to the future, it may be possible to expand the use of these drugs through greater understanding of which patients are likely to benefit most and, in the case of teriparatide, by the emergence of biosimilars. Greater understanding is also needed as to how best to integrate these treatments with conventional antiresorptive agents in the form of sequential or even combination therapy. The benefit of repeated treatment courses also warrants further examination, with a focus on the clinically relevant outcome of fracture risk reduction rather than solely changes in BMD.
1. Kanis JA, Melton LJ, Christiansen C, et al:: The diagnosis of osteoporosis. J Bone Miner Res. 1994; 9(8): 1137-41. PubMed Abstract | Publisher Full Text

2. Hernlund $E$, Svedbom A, Ivergård M, et al: Osteoporosis in the European Union: Medical management, epidemiology and economic burden. A report prepared in collaboration with the International Osteoporosis Foundation (IOF) and the European Federation of Pharmaceutical Industry Associations (EFPIA). Arch Osteoporos. 2013; 8(1): 136.

PubMed Abstract | Publisher Full Text | Free Full Text

3. Cree $\mathrm{M}$, Soskolne $\mathrm{CL}$, Belseck $\mathrm{E}$, et al:: Mortality and institutionalization following hip fracture. J Am Geriatr Soc. 2000; 48(3): 283-8. PubMed Abstract | Publisher Full Text

4. Cauley JA, Thompson DE, Ensrud KC, et al.: Risk of mortality following clinical fractures. Osteoporos Int. 2000; 11(7): 556-61. PubMed Abstract | Publisher Full Text

5. Tosteson AN, Gabriel SE, Grove MR, et al.: Impact of hip and vertebral fractures on quality-adjusted life years. Osteoporos Int. 2001; 12(12): 1042-9. PubMed Abstract | Publisher Full Text

6. Black DM, Thompson DE, Bauer DC, et al.: Fracture risk reduction with alendronate in women with osteoporosis: The Fracture Intervention Trial. FIT Research Group. J Clin Endocrinol Metab. 2000; 85(11): 4118-24. PubMed Abstract | Publisher Full Text

7. Reginster J, Minne HW, Sorensen $\mathrm{OH}$, et al:: Randomized trial of the effects of risedronate on vertebral fractures in women with established postmenopausal osteoporosis. Vertebral Efficacy with Risedronate Therapy (VERT) Study Group. Osteoporos Int. 2000; 11(1): 83-91. PubMed Abstract | Publisher Full Text

8. McClung MR, Geusens P, Miller PD, et al:: Effect of risedronate on the risk of hip fracture in elderly women. Hip Intervention Program Study Group. N Engl J Med. 2001; 344(5): 333-40.

PubMed Abstract | Publisher Full Text

9. Chesnut $\mathrm{CH}, \mathrm{Skag} \mathrm{A}$, Christiansen $\mathrm{C}$, et al.: Effects of oral ibandronate administered daily or intermittently on fracture risk in postmenopausal osteoporosis. J Bone Miner Res. 2004; 19(8): 1241-9. PubMed Abstract | Publisher Full Text

10. Black DM, Delmas PD, Eastell R, et al:: Once-yearly zoledronic acid for treatment of postmenopausal osteoporosis. N Engl J Med. 2007; 356(18): 1809-22.

PubMed Abstract | Publisher Full Text
11. Cummings SR, San Martin J, McClung MR, et al.: Denosumab for prevention of fractures in postmenopausal women with osteoporosis. N Engl J Med. 2009; 361(8): 756-65.

PubMed Abstract | Publisher Full Text | Faculty Opinions Recommendation

12. Reyes $C$, Hitz M, Prieto-Alhambra D, et al:: Risks and Benefits of Bisphosphonate Therapies. J Cell Biochem. 2016; 117(1): 20-8. PubMed Abstract | Publisher Full Text

13. Hiligsmann $M$, Cornelissen D, Vrijens B, et al.: Determinants, consequences and potential solutions to poor adherence to anti-osteoporosis treatment: Results of an expert group meeting organized by the European Society for Clinical and Economic Aspects of Osteoporosis, Osteoarthritis and Musculoskeletal Diseases (ESCEO) and the International Osteoporosis Foundation (IOF). Diseases (ESCEO) and the International
Osteoporos Int. 2019; 30(11): 2155-65. Osteoporos Int. 2019; 30(11): 2155-65.
PubMed Abstract | Publisher Full Text | Free Full Text

14. Tam CS, Heersche JN, Murray TM, et al:: Parathyroid hormone stimulates the bone apposition rate independently of its resorptive action: Differential effects of intermittent and continuous administration. Endocrinology. 1982; 110(2): 506-12.

PubMed Abstract | Publisher Full Text

15. Silverberg SJ, Shane E, de La Cruz L, et al:: Skeletal disease in primary hyperparathyroidism. J Bone Miner Res. 1989; 4(3): 283-91. PubMed Abstract | Publisher Full Text

16. Neer RM, Arnaud CD, Zanchetta JR, et al:: Effect of parathyroid hormone (134 ) on fractures and bone mineral density in postmenopausal women with osteoporosis. N Engl J Med. 2001; 344(19): 1434-41. PubMed Abstract | Publisher Full Text

17. Finkelstein JS, Wyland JJ, Lee H, et al.: Effects of teriparatide, alendronate, or both in women with postmenopausal osteoporosis. J Clin Endocrinol Metab. 2010; 95(4): 1838-45. PubMed Abstract | Publisher Full Text | Free Full Text

18. S Saag KG, Shane E, Boonen S, et al:: Teriparatide or alendronate in glucocorticoid-induced osteoporosis. N Engl J Med. 2007; 357(20): 2028-39. PubMed Abstract | Publisher Full Text | Faculty Opinions Recommendation

19. Hadji P, Zanchetta JR, Russo L, et al.: The effect of teriparatide compared with risedronate on reduction of back pain in postmenopausal women with osteoporotic vertebral fractures. Osteoporos Int. 2012; 23(8): 2141-50. PubMed Abstract | Publisher Full Text

20. Kendler DL, Marin F, Zerbini CAF, et al:: Effects of teriparatide and 
risedronate on new fractures in post-menopausal women with severe osteoporosis (VERO): A multicentre, double-blind, double-dummy, randomised controlled trial. Lancet. 2018; 391(10117): 230-240. PubMed Abstract | Publisher Full Text | Faculty Opinions Recommendation

21. Díez-Pérez A, Marin F, Eriksen EF, et al:: Effects of teriparatide on hip and upper limb fractures in patients with osteoporosis: A systematic review and meta-analysis. Bone. 2019; 120: 1-8.

PubMed Abstract | Publisher Full Text | Faculty Opinions Recommendation

22. Vahle JL, Long GG, Sandusky G, et al.: Bone neoplasms in F344 rats given teriparatide rhPTH(1-34) are dependent on duration of treatment and dose. Toxicol Pathol. 2004; 32(4): 426-38.

PubMed Abstract | Publisher Full Text

23. Andrews EB, Gilsenan AW, Midkiff $\mathrm{K}$, et al:: The US postmarketing surveillance study of adult osteosarcoma and teriparatide: Study design and findings from the first 7 years. J Bone Miner Res. 2012; 27(12): 2429-37. PubMed Abstract | Publisher Full Text | Free Full Text

24. Koller G, Goetz V, Vandermeer B, et al.: Persistence and adherence to parenteral osteoporosis therapies: A systematic review. Osteoporos Int. 2020; 31(11): 2093-2102.

PubMed Abstract | Publisher Full Text

25. Nakamura T, Sugimoto T, Nakano T, et al.: Randomized Teriparatide human parathyroid hormone (PTH) 1-34 Once-Weekly Efficacy Research (TOWER) trial for examining the reduction in new vertebral fractures in subjects with primary osteoporosis and high fracture risk. J Clin Endocrinol Metab. 2012; 97(9): 3097-106

PubMed Abstract | Publisher Full Text | Faculty Opinions Recommendation

26. Sugimoto $\mathrm{T}$, Shiraki M, Fukunaga M, et al:: Study of twice-weekly injections of Teriparatide by comparing efficacy with once-weekly injections in osteoporosis patients: The TWICE study. Osteoporos Int. 2019; 30(11) 2321-2331.

PubMed Abstract | Publisher Full Text | Free Full Text

27. Compston J, Cooper A, Cooper C, et al.: UK clinical guideline for the prevention and treatment of osteoporosis. Arch Osteoporos. 2017; 12(1): 43. PubMed Abstract | Publisher Full Text | Free Full Text

28. Cosman F, Nieves JW, Dempster DW: Treatment Sequence Matters: Anabolic and Antiresorptive Therapy for Osteoporosis. $J$ Bone Miner Res. 2017; 32(2): 198-202.

PubMed Abstract | Publisher Full Text | Faculty Opinions Recommendation

29. Leder BZ, Tsai JN, Uihlein AV, et al.: Denosumab and teriparatide transitions in postmenopausal osteoporosis (the DATA-Switch study): Extension of a randomised controlled trial. Lancet. 2015; 386(9999): 1147-55. PubMed Abstract | Publisher Full Text | Free Full Text | Faculty Opinions Recommendation

30. Lou S, Lv H, Yin P, et al:: Combination therapy with parathyroid hormone analogs and antiresorptive agents for osteoporosis: A systematic review and meta-analysis of randomized controlled trials. Osteoporos Int. 2019; 30(1) 59-70.

PubMed Abstract | Publisher Full Text | Faculty Opinions Recommendation

31. C Geusens P, Marin F, Kendler DL, et al:: Effects of Teriparatide Compared with Risedronate on the Risk of Fractures in Subgroups of Postmenopausa Women with Severe Osteoporosis: The VERO Trial. J Bone Miner Res. 2018; 33(5): 783-794.

PubMed Abstract | Publisher Full Text | Faculty Opinions Recommendation

32. Black DM, Bilezikian JP, Ensrud KE, et al.: One year of alendronate after one year of parathyroid hormone (1-84) for osteoporosis. N Engl J Med. 2005; 353(6): 555-65.

PubMed Abstract | Publisher Full Text

33. Finkelstein JS, Wyland JJ, Leder BZ, et al.: Effects of teriparatide retreatment in osteoporotic men and women. J Clin Endocrinol Metab. 2009; 94(7): 2495-501. PubMed Abstract | Publisher Full Text | Free Full Text

34. Gatti D, Viapiana O, Idolazzi L, et al.: The waning of teriparatide effect on bone formation markers in postmenopausal osteoporosis is associated with increasing serum levels of DKK1. J Clin Endocrinol Metab. 2011; 96(5): 1555-9. PubMed Abstract | Publisher Full Text

35. Hattersley G, Dean T, Corbin BA, et al.: Binding Selectivity of Abaloparatide for PTH-Type-1-Receptor Conformations and Effects on Downstream Signaling. Endocrinology. 2016; 157(1): 141-9. PubMed Abstract | Publisher Full Text | Free Full Text | Faculty Opinions Recommendation

36. Miller PD, Hattersley G, Riis BJ, et al.: Effect of Abaloparatide vs Placebo on New Vertebral Fractures in Postmenopausal Women With Osteoporosis: A Randomized Clinical Trial. JAMA. 2016; 316(7): 722-33. PubMed Abstract | Publisher Full Text | Faculty Opinions Recommendation

37. Bone HG, Cosman F, Miller PD, et al:: ACTIVExtend: 24 Months of Alendronate After 18 Months of Abaloparatide or Placebo for Postmenopausal Osteoporosis. J Clin Endocrinol Metab. 2018; 103(8): 2949-2957. PubMed Abstract | Publisher Full Text | Free Full Text | Faculty Opinions Recommendation

38. EMA: Refusal of the Marketing Authorisation for Eladynos (Abaloparatide).
European Medicines Agency. 2018

Reference Source

39. Balemans W, Ebeling M, Patel N, et al.: Increased bone density in sclerosteosis is due to the deficiency of a novel secreted protein (SOST). Hum Mol Genet. 2001; 10(5): 537-43.

PubMed Abstract | Publisher Full Text

40. N McClung MR, Grauer A, Boonen S, et al.: Romosozumab in postmenopausal women with low bone mineral density. N Engl J Med. 2014; 370(5): 412-20. PubMed Abstract | Publisher Full Text | Faculty Opinions Recommendation

41. Cosman F, Crittenden DB, Adachi JD, et al.: Romosozumab Treatment in Postmenopausal Women with Osteoporosis. N Engl J Med. 2016; 375(16): 1532-1543.

PubMed Abstract | Publisher Full Text | Faculty Opinions Recommendation

42. Cosman F, Crittenden DB, Ferrari S, et al.: Romosozumab FRAME Study: A Post Hoc Analysis of the Role of Regional Background Fracture Risk on Nonvertebral Fracture Outcome. J Bone Miner Res. 2018; 33(8): 1407-1416. PubMed Abstract | Publisher Full Text

43. Lewiecki EM, Dinavahi RV, Lazaretti-Castro M, et al.: One Year of Romosozumab Followed by Two Years of Denosumab Maintains Fracture Risk Reductions: Results of the FRAME Extension Study. J Bone Miner Res. 2019; 34(3): 419-428.

PubMed Abstract | Publisher Full Text | Faculty Opinions Recommendation

44. Saag KG, Petersen J, Brandi ML, et al:: Romosozumab or Alendronate for Fracture Prevention in Women with Osteoporosis. N Engl J Med. 2017; 377(15): 1417-1427.

PubMed Abstract | Publisher Full Text | Faculty Opinions Recommendation

45. Kendler DL, Bone HG, Massari F, et al.: Bone mineral density gains with a second 12-month course of romosozumab therapy following placebo or denosumab. Osteoporos Int. 2019; 30(12): 2437-2448. PubMed Abstract | Publisher Full Text | Free Full Text

46. L Lv F, Cai X, Yang W, et al.: Denosumab or romosozumab therapy and risk of cardiovascular events in patients with primary osteoporosis: Systematic review and meta- analysis. Bone. 2020; 130: 115121 PubMed Abstract | Publisher Full Text | Faculty Opinions Recommendation

47. Fuggle NR, Cooper C, Harvey NC, et al:: Assessment of Cardiovascular Safety of Anti-Osteoporosis Drugs. Drugs. 2020; 80(15): 1537-1552. PubMed Abstract | Publisher Full Text | Free Full Text | Faculty Opinions Recommendation

48. Cummings SR, McCulloch C: Explanations for the difference in rates of cardiovascular events in a trial of alendronate and romosozumab. Osteoporos Int. 2020; 31(6): 1019-1021.

PubMed Abstract | Publisher Full Text

49. Bovijn J, Krebs K, Chen CY, et al.: Evaluating the cardiovascular safety of sclerostin inhibition using evidence from meta-analysis of clinical trials and human genetics. Sci Transl Med. 2020; 12(549): eaay6570. PubMed Abstract | Publisher Full Text | Free Full Text

50. Reid IR, Horne AM, Mihov B, et al.: Fracture Prevention with Zoledronate in Older Women with Osteopenia. N Engl J Med. 2018; 379(25): 2407-2416. PubMed Abstract | Publisher Full Text

51. Reid IR, Horne AM, Mihov B, et al:: Effects of Zoledronate on Cancer, Cardiac Events, and Mortality in Osteopenic Older Women. J Bone Miner Res. 2020; 35(1): 20-27.

PubMed Abstract | Publisher Full Text | Faculty Opinions Recommendation

52. C Cummings SR, Lui LY, Eastell R, et al:: Association Between Drug Treatments for Patients With Osteoporosis and Overall Mortality Rates: A Meta-analysis. JAMA Intern Med. 2019; 179(11): 1491-1500. PubMed Abstract | Publisher Full Text | Free Full Text | Faculty Opinions Recommendation

53. Schnell AD, Curtis JR, Saag KG: Importance of Recent Fracture as Predictor of Imminent Fracture Risk. Curr Osteoporos Rep. 2018; 16(6): 738-745. PubMed Abstract | Publisher Full Text | Faculty Opinions Recommendation

54. Legrand MA, Chapurlat R: Imminent fracture risk. Joint Bone Spine. 2020; 88(3): 105105.

PubMed Abstract | Publisher Full Text

55. Roux C, Briot K: Imminent fracture risk. Osteoporos Int. 2017; 28(6): 1765-1769 PubMed Abstract | Publisher Full Text

56. Johansson $\mathrm{H}$, Siggeirsdóttir K, Harvey NC, et al.: Imminent risk of fracture after fracture. Osteoporos Int. 2017; 28(3): 775-780.

PubMed Abstract | Publisher Full Text | Free Full Text

57. Balasubramanian A, Zhang J, Chen L, et al:: Risk of subsequent fracture after prior fracture among older women. Osteoporos Int. 2019; 30(1): 79-92. PubMed Abstract | Publisher Full Text | Free Full Text

58. Kanis JA, Harvey NC, McCloskey E, et al:: Algorithm for the management of patients at low, high and very high risk of osteoporotic fractures. Osteoporos Int. 2020; 31(1): 1-12.

PubMed Abstract | Publisher Full Text | Free Full Text

Faculty Opinions Recommendation 
59. Kanis JA, Johansson H, Harvey NC, et al:: Adjusting conventional FRAX estimates of fracture probability according to the recency of sentinel fractures. Osteoporos Int. 2020; 31(10): 1817-1828. PubMed Abstract | Publisher Full Text | Free Full Text

60. National Institute for Heath and Care Excellence: Raloxifene and Teriparatide for the Secondary Prevention of Osteoporotic Fragility Fractures in Postmenopausal Women [TA161]. 2008. (accessed 16 September 2020). Reference Source

61. D Davis S, Simpson E, Hamilton J, et al:: Denosumab, raloxifene, romosozumab and teriparatide to prevent osteoporotic fragility fractures: A systematic review and economic evaluation. Health Technol Assess. 2020; 24(29): 1-314

PubMed Abstract | Publisher Full Text | Free Full Text |

Faculty Opinions Recommendation
62. Li N, Cornelissen D, Silverman S, et al:: An Updated Systematic Review of Cost-Effectiveness Analyses of Drugs for Osteoporosis. Pharmacoeconomics. 2021; 39(2): 181-209.

PubMed Abstract | Publisher Full Text | Free Full Text |

Faculty Opinions Recommendation

63. Mori T, Crandall CJ, Ganz DA: Cost-Effectiveness of Sequential Teriparatide/ Alendronate Versus Alendronate-Alone Strategies in High-Risk Osteoporotic Women in the US: Analyzing the Impact of Generic/Biosimilar Teriparatide. JBMR Plus. 2019; 3(11): e10233.

PubMed Abstract | Publisher Full Text | Free Full Text

64. Söreskog E, Lindberg I, Kanis JA, et al:: Cost-effectiveness of romosozumab for the treatment of postmenopausal women with severe osteoporosis at high risk of fracture in Sweden. Osteoporos Int. 2021; 32(3): 585-594.

PubMed Abstract | Publisher Full Text | Free Full Text 